\title{
Effect of NiO Filler on the Dielectric Constant and morphology of ZnO using Solid State Method at Microwave Frequency
}

\author{
Sani Garba Danjumma \\ Department of Sciences \\ Kebbi State Polytechnic, Dakingari, Nigeria
}

\author{
Abubakar Yakubu \\ Department of Physics \\ Kebbi State Univ. of Sci. and Tech. Aliero, Nigeria
}

\author{
Sahabi Suleiman \\ Department of Sciences \\ Kebbi State Polytechnic, Dakingari, Nigeria
}

\author{
Saidu Aliyu \\ Department of Sciences \\ Kebbi State Polytechnic, Dakingari, Nigeria \\ Sirajo Abdullahi \\ Department of Physics \\ Kebbi State Univ. of Sci. and Tech. Aliero, Nigeria
}

\begin{abstract}
Dielectric materials have many important functions in the microelectronics industry. The aim of this research is to characterize the dielectric constant of doped zinc-oxide composites using solid state method at microwave frequency. The methods used in this research are solid state method for sample preparation, open ended coaxial probe (OECP) for determining the dielectric constant and FTIR for bonding and IR absorption properties. The OECP results shows a sequential increase in dielectric constant as pure $\mathrm{ZnO}$ is doped incrementally with the filler ( $\mathrm{NiO})$. It also shows a sequential decrease in dielectric constant as the frequency increases. The FTIR result shows an increase in IR absorption as NiO content increases. The result from SEM was able to distinguish between the filler and matrix for each composition. Therefore $\mathrm{NiO}$ can be used as a filler for improving dielectric constant of $\mathrm{ZnO}$ as a matrix. The composite can also serve as a good agent for constructing capacitors and other dielectric materials which are hence used in manufacturing electronic and telecommunication gadgets. It was also proven that solid state method is a good method for synthesis of powdered sample like $\mathrm{ZnO}$ and $\mathrm{NiO}$ for determining their dielectric constant.
\end{abstract}

Key Words - Nickel Oxide (NiO); Zinc Oxide (ZnO); Dielectric Constant; Solid State Method; Microwave Frequency

\section{INTRODUCTION}

Mixed oxide nanocomposites are being studied because of their potential for enhanced functional performance in photocatalysis, sensors and other optoelectronic device applications. $\mathrm{ZnO}$ is a wide band gap (3.2 eV) n-type semiconductor that has found a wide range of applications as a transparent conducting oxide (TCO) electrode in photovoltaics, photocatalysis, sensing, fuel cells and other optoelectronic devices (Albert \& Abiola, 2017). Umit, (2010), reported that, $\mathrm{ZnO}$ is an attractive material for applications in electronics, photonics, acoustics, and sensing. In optical emitters, its high exciton binding energy (60 meV) gives $\mathrm{ZnO}$ an edge over other semiconductors such as GaN if reproducible and reliable p-type doping in $\mathrm{ZnO}$ were to be achieved, which currently remains to be the main obstacle for realization of bipolar devices. On the electronic side, $\mathrm{ZnO}$ holds some potential in transparent thin film transistors (TFTs) owing to its high optical transmittivity and high conductivity.

$\mathrm{NiO}$ is a p-type wide band gap $(4.2 \mathrm{eV})$ semiconductor that has been used in similar applications. $\mathrm{ZnO}$ and $\mathrm{NiO}$ readily form a p-n junction that has shown good electrical properties for gas sensing, fuel cell electrodes and photocatalysis (Albert and Abiola, 2017). The applications of Nickel oxide $(\mathrm{NiO})$ today is found in semiconductors, capacitor-inductor devices, tuned circuits, transparent heat mirrors, thermistors and varistors, batteries, micro-supercapacitors, electrochromic and chemical or temperature sensing devices. It is used in preparation of nickel cermet, plastics and textiles, in nanowires, nanofibers and specific alloy and catalyst applications. It is also used as an antiferromagnetic layers, accelerators and radar absorbing materials, aerospace and active optical filters (Sani et al., 2019; AzoNano, 2013). Ghassan and Naeem (2016), in their research investigated the effect of volume filler content $\phi$ on dielectric constant of polyethylene PE filled with nickel (Ni) powders. They observed that, the dielectric constant of such composites increase suddenly at a critical volume concentration indicating a semi-conducting behaviour. Aldar et al. (2014), reported that the dielectric constant decreases with increase in frequency. The dielectric constant decreases rapidly at low frequencies and becomes quite slow at high frequencies. The higher value of dielectric constant at lower frequencies is explained on the basis of space charge polarization. Ranga et al. (1999), investigated the dielectric constant of polycrystalline mixed nickel-zinc ferrites in the frequency range $100 \mathrm{kHz}-1 \mathrm{MHz}$. It was shown that, the dielectric constant for these ferrites is approximately inversely proportional to the square root of the resistivity. John et al. (2008), prepared nanostructured nickel ferrite samples through a chemical precipitation method followed by thermal processes. The dielectric constant was studied and the nanoparticles of nickel ferrite showed substantial variation in the values of dielectric constants.

A series of nanocomposites of nickel-zinc ferrite + paraformaldehyde was successfully synthesized using the mechanical milling process. With the increase in the volume of polymer, the dielectric constants of all the composites 
decreases (Raju \& Murphy, 2012). Nickel nanocomposites were synthesized by thermal decomposition route. The dielectric constant, was observed to decrease rapidly with increase in frequency in the low frequency range and it reach a constant value at the high frequency range which is independent of frequency (Sourav et al., 2014). The composite of oil palm empty fruit bunch fiber (OPEFB) which is the waste product of oil palm industry, environmentally friendly polycaprolactone (PCL) and nickel oxide $(\mathrm{NiO})$ were fabricated by compounding all materials in the Thermo Haake blending machine. The dielectric constants of the substrates were obtained with the open ended coaxial method for microwave frequency range between $0.2 \mathrm{MHz}$ and $20 \mathrm{GHz}$. The results revealed that the permittivity values of the composite can be tuned by changing the ratio of OPEFB/PCL/NiO prior to compounding and blending (Ahmad et al., 2015).

Gaurav et al. (2015), studied the improvement in dielectric constant of nematic liquid crystal (NLC) by doping of nickel oxide $(\mathrm{NiO})$ nanoparticles. They observed that the dielectric constant decrease as the frequency increases.

Ajai et al. (2017), synthesized conducting polyaniline-nickel ferrite (PANI/NiFe $\mathrm{O}_{4}$ ) composites by employing interfacial polymerization method. The dielectric constant of $\mathrm{PANI} / \mathrm{NiFe} 2 \mathrm{O}_{4}$ composites are large at lower frequencies and decrease steeply with increasing frequency. Ramesh $e t$ al. (2003), measured ultralow dielectric constant values on $\mathrm{Ni}-\mathrm{Zn}$ ferrites prepared using $\mathrm{Fe}_{2} \mathrm{O}_{3}$ as a starting material and sintered in a microwave field. Dielectric properties were observed between microwave-sintered $\mathrm{Ni}-\mathrm{Zn}$ ferrites prepared using $\mathrm{Fe}_{3} \mathrm{O}_{4}$ (T34) and those starting with $\mathrm{Fe}_{2} \mathrm{O}_{3}$ (T23) ingredients. The ultralow dielectric constant values observed on T23 ferrites show that this procedure is highly suitable to prepare $\mathrm{Ni}-\mathrm{Zn}$ ferrites for high-frequency switching applications. Bahari et al. (2012), fabricated polyvinylpyrrolidone / Nickel oxide (PVP/NiO) dielectrics with sol-gel method using $0.2 \mathrm{~g}$ of PVP at different working temperatures of 80,150 and $200{ }^{\circ} \mathrm{C}$. The obtained results demonstrate the feasibility of using high dielectric constant nanocomposite $\mathrm{PVP} / \mathrm{NiO}$ as gate dielectric insulator in the organic thin film transistors (OTFTs).

Banerjee et al. (2012), synthesized Barium strontium titanate (BST) ceramics $\left(\mathrm{Ba}_{0.6} \mathrm{Sr}_{0.4}\right) \mathrm{TiO}_{3}$ by solid state sintering using barium carbonate, strontium carbonate and rutile as the precursor materials. The samples were doped with nickel oxide in different proportions. It was observed that the dielectric properties of BST were modified significantly with nickel oxide doping. Muhammad et al. (2012), focus on the preparation of nickel oxide nanocrystallites by a novel low cost sol-gel auto-combustion technique and the dielectric constant was studied. The value of dielectric constant decreased with the increase of frequency up to $1 \mathrm{MHz}$, which they attributed to the space charge polarization. Rajashekhar et al. (2015), synthesized $\mathrm{NiO}$ nanoparticles by self-propagating high temperature (SHS) method. These synthesized NNP are used to blend with PANI to get PANI -NiO (PN) composites. The result of the dielectric behaviour of the above synthesized nanocomposites suites for battery applications.
The FTIR spectra for pure PVA, ZnO/ PVA nanocomposite films and $\mathrm{ZnO}$ are reported by Mansour, et al. (2014). In the spectra of pure PVA and $\mathrm{ZnO} / \mathrm{PVA}$ nanocomposites, the broad and strong band centered at $3340 \mathrm{~cm}^{-1}$ is assigned to the stretching vibration of hydroxyl group $(\mathrm{OH})$. The strong band at $2940 \mathrm{~cm}^{-1}$ is assigned to the band of asymmetric $\mathrm{CH}_{2}$ stretching. The two bands observed at 1712 and 1658 $\mathrm{cm}-1$ are assigned to the stretching vibrational band of $\mathrm{C}=\mathrm{O}$. The two bands observed at 1427 and $1330 \mathrm{~cm}-1$ are assigned as $\mathrm{CH}_{3}$ bending vibration and $\mathrm{CH} 2$ stretching respectively. The band at $1090 \mathrm{~cm}^{-1}$ arises from the $\mathrm{C}-\mathrm{O}$ stretching vibration while the band at $920 \mathrm{~cm}-1$ results from $\mathrm{CH}_{2}$ rocking vibration. Also, the band at $850 \mathrm{~cm}^{-1} 1$ result from $\mathrm{C}_{-}$ $\mathrm{C}$ stretching vibration and that at $660 \mathrm{~cm}^{-1}$ arises from out of plane $\mathrm{OH}$ bending. The band at $432 \mathrm{~cm}^{-1}$ is assigned to the stretching vibration of $\mathrm{Zn}-\mathrm{O}$ bond. FTIR spectra of PVA, $\mathrm{ZnO}$ and $\mathrm{ZnO} / \mathrm{PVA}$ nanocomposites indicating that there are no interactions between polyvinyl alcohol and zinc oxide in forming nanocomposites.

Nisha et al. (2008), prepared nanoparticles of nickel-cobalt oxide by chemical co-precipitation method. The effect of frequency on the dielectric behaviour have been studied for nanosized samples of nickel-cobalt spinel oxide. It is seen that, with the decreasing frequency, the dielectric constant increases much more obviously than that of the conventional materials. Osama et al. (2014), reported that, addition of $\mathrm{SiO}_{2}$ in the presence of $\mathrm{ZnO}$ and $\mathrm{NiO}$ leads to better densification by minimizing the present of closed pores. Results of firing shrinkage as a function of temperature show increase of shrinkage with temperature. The dielectric constant shows a decreasing trend for all the samples, the decrease is rapid at lower frequency and slower and stable at higher frequency.

Latif et al. (2012), investigated the dielectric behavior of the polar (CPVA) / ZnO nanocomposite films. The results show that the dopant composition has great influence on the magnitude of dielectric properties. The results also show that the composite polymer films have both electric and electronic properties. Wang et al. 2017), prepared the samples of $1 \%, 2 \%, 3 \%$ and $4 \%$ Zinc Oxide $(\mathrm{ZnO})$ nanocomposite silicone rubber by mechanical method. The dielectric properties of each sample were measured by dielectric spectroscopy. The experimental results showed that the dielectric constant of the silicone rubber composite increases with the increase of the content of nano- $\mathrm{ZnO}$. Suresh et al. (2017), used the sol-gel technique in the chemical synthesis and characterizations based on electrical studies of pure and Ag-doped zinc oxide $(\mathrm{ZnO})$ nanoparticles. The dielectric studies proved that both the dielectric constant reduces as the frequency increases.

From the review above, so many methods of preparation were chosen but only Banerjee et al. (2012), used solid state which is very cheap and environmentally friendly. The final product remained in solid form and structurally pure with the desired properties. Instead of Barium strontium titanate as in the case of Banerjee et al. (2012), $\mathrm{ZnO}$ is doped with $\mathrm{NiO}$ in this research and among other advantages of $\mathrm{ZnO}$ are significant physical and chemical stabilities, high catalytic 
activity, effective antibacterial and bactericide function, and intensive ultraviolet and infrared absorption.

\section{EXPERIMENT}

\section{A. Sample Preparation}

In this work, the solid state method is used in the preparation of a doped zinc oxide. The materials used for the synthesis are $100 \mathrm{~g}$ of Zinc oxide (99.7\% purity) and $50 \mathrm{~g}$ of Nickel oxide (99.7\% purity) all in powdered form. The Zinc oxide was obtained at Halishuaib Chemicals while the Nickel oxide was obtained at CEMAN Chemicals Ventures. During the preparation of the composites, $5 \mathrm{~g}$ of Nickel oxide was mixed with $25 \mathrm{~g}$ of Zinc oxide using pestle and mortar, the combination was grinded continuously using mortar and pestle for about 60 minutes for perfect homogeneity. The mixed sample was taken to furnace and was heated to about $1000^{\circ} \mathrm{C}$ for appreciable reaction to take place. The same procedure was applied for $7.5 \mathrm{~g}$ of Nickel oxide and $22.5 \mathrm{~g}$ of Zinc oxide, $10 \mathrm{~g}$ of Nickel oxide and $20 \mathrm{~g}$ of Zinc oxide, $12.5 \mathrm{~g}$ of Nickel oxide and $17.5 \mathrm{~g}$ of Zinc oxide, and $15 \mathrm{~g}$ of Nickel oxide and $15 \mathrm{~g}$ of Zinc oxide. Five different mixtures with different proportions of Zinc oxide and Nickel oxide were prepared. The summary of materials composition is shown in Table 1 . The prepared composites are then ready for characterization.

TABLE 1: COMPOSITION OF SAMPLES

\begin{tabular}{|c|c|c|c|c|c|c|}
\hline \multirow{2}{*}{ Sample } & \multicolumn{2}{|c|}{ NiO } & \multicolumn{2}{c|}{ ZnO } & \multicolumn{2}{c|}{ Total } \\
\cline { 2 - 7 } & $(g)$ & $\%$ & $(g)$ & $\%$ & $(g)$ & $\%$ \\
\hline $\mathrm{A}$ & 5.0 & 16.7 & 25.0 & 83.3 & 30.0 & 100 \\
\hline $\mathrm{B}$ & 7.5 & 25.0 & 22.5 & 75.0 & 30.0 & 100 \\
\hline $\mathrm{C}$ & 10.0 & 33.3 & 20.0 & 66.7 & 30.0 & 100 \\
\hline $\mathrm{D}$ & 12.5 & 41.7 & 17.5 & 58.3 & 30.0 & 100 \\
\hline $\mathrm{E}$ & 15.0 & 50 & 15.0 & 50 & 30.0 & 100 \\
\hline
\end{tabular}

B. Characterization

Characterization of the samples for dielectric constant were carried out using open ended coaxial probe HP85071C within a microwave frequency range of 8.2 to $12.2 \mathrm{GHz}$. The bonding and IR absorption of the samples were studied using FTIR within the range of 750 to $4000 \mathrm{~cm}^{-1}$ wavenumber.

III.

\section{RESULTS AND DISCUSSION}

\section{A. Dielectric Constant}

After measuring all the samples under study, the raw data obtained was then used to plot the dielectric constant. Shown in Fig. 3.1 is the comparison of the dielectric constant obtained for all the samples.

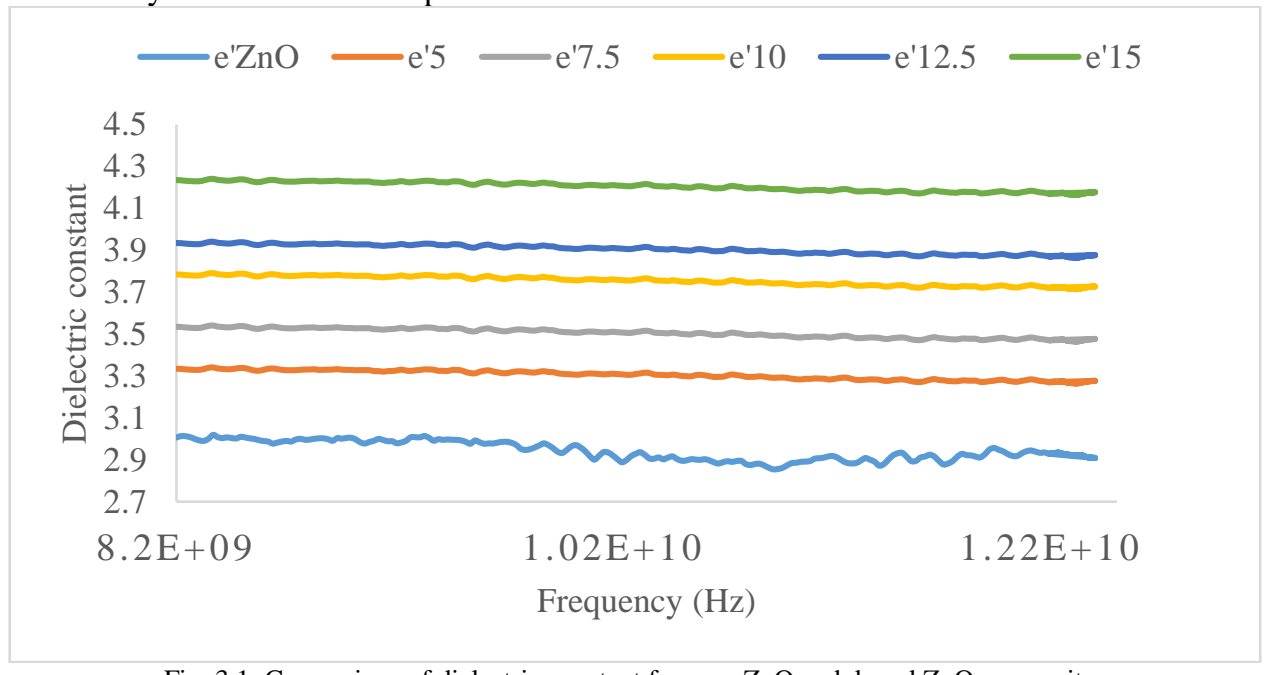

Fig. 3.1: Comparison of dielectric constant for pure $\mathrm{ZnO}$ and doped $\mathrm{ZnO}$ composites

The graph shown in Fig. 3.1 depicts a sequential increase in dielectric constant as pure $\mathrm{ZnO}$ is doped incrementally with the filler $(\mathrm{NiO})$. The results shows a total increase in dielectric of 1.22 representing $40.0 \%$. Further observation shows that dielectric constant decreased as frequency increases for all samples. This result is in agreement with (Ahmad et al., 2017), who observed in his research an increase in the dielectric properties of polymer as it is doped with nikel-ferrrite. The same thing was also confirm by Sylvestre et al. (2007), who reported that the dielectric constant of Nickel/hydrogenated amorphous carbon dropped from 300 to 200 as the frequency increased from $1 \mathrm{~Hz}$ to 10 $\mathrm{kHz}$.

At $8.2 \mathrm{GHz}$, it was observed that the pure $\mathrm{ZnO}$ have a dielectric constant of 3.01, $5 \mathrm{~g}$ doped $\mathrm{ZnO}$ have 3.33, $7.5 \mathrm{~g}$ doped $\mathrm{ZnO}$ have 3.53, $10 \mathrm{~g}$ doped $\mathrm{ZnO}$ have $3.78,12.5 \mathrm{~g}$ doped $\mathrm{ZnO}$ have 3.93 and $15 \mathrm{~g}$ doped $\mathrm{ZnO}$ have 4.23 . Similarly, at $10.2 \mathrm{GHz}$, it was observed that the pure $\mathrm{ZnO}$ have a dielectric constant of 2.91, $5 \mathrm{~g}$ doped $\mathrm{ZnO}$ have 3.31,
$7.5 \mathrm{~g}$ doped $\mathrm{ZnO}$ have $3.51,10 \mathrm{~g}$ doped $\mathrm{ZnO}$ have $3.76,12.5$ $\mathrm{g}$ doped $\mathrm{ZnO}$ have 3.91 and $15 \mathrm{~g}$ doped $\mathrm{ZnO}$ have 4.21. This shows an increase in dielectric constant as $\mathrm{NiO}$ is added (Sylvestre et al., 2007) to the $\mathrm{ZnO}$. It also revealed a decrease in dielectric constant as the frequency increases. The decrease in dielectric constant with frequency indicates dielectric dispersion is at low frequency region which is due to Maxwell-Wagner type of interfacial polarization in agreement with Koop's phenomenological theory (Yakubu et al., 2015). The dielectric constant decreases rapidly at low frequencies and becomes quite slow at high frequencies. The higher value of dielectric constant at lower frequencies is explained on the basis of space charge polarization (Aldar et al., 2014; Muhammad et al., 2012). However, Sourav et al. (2014) reported that high value of dielectric constant at low frequency and almost constant value at higher frequency is due hopping contribution. Yakubu et al. (2015), reported that high value of dielectric constant at lower frequencies is 
attributed to the interfacial ionic polarizations due to localized ion motion within the sample.

$$
\text { B. FTIR }
$$

Fig. 3.2 and 3.3 are the results obtained from FTIR spectroscopy for the $41.7 \%$, and $50.0 \%$ doped $\mathrm{ZnO}$ composites, respectively. They were acquired in the range of 750 to $4000 \mathrm{~cm}^{-1}$ wavenumber, with a maximum transmittance of $100 \%$.

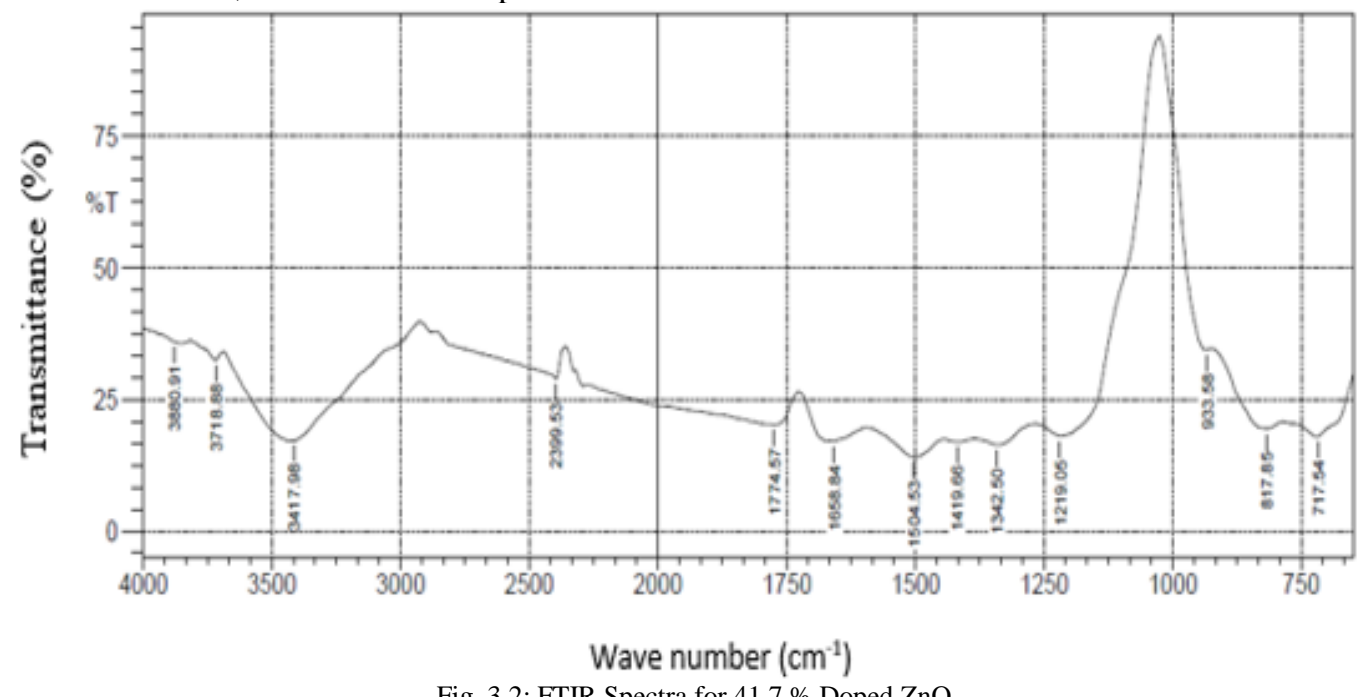

Fig. 3.2: FTIR Spectra for $41.7 \%$ Doped $\mathrm{ZnO}$

The FTIR spectrum in Fig. 3.2 shows the absorption region of $717.54 \mathrm{~cm}^{-1}, 817.85 \mathrm{~cm}^{-1}, 1219.05 \mathrm{~cm}^{-1}, 1342.50 \mathrm{~cm}^{-1}$, $1419.00 \mathrm{~cm}^{-1}, 1504.53 \mathrm{~cm}^{-1}, 1658.84 \mathrm{~cm}^{-1}, 1774.57 \mathrm{~cm}^{-1}$ and $3417.90 \mathrm{~cm}^{-1}$. The highest absorbance observed is $86 \%$ at $1504.53 \mathrm{~cm}^{-1}$ corresponding to $14 \%$ transmittance. The absorption band observed at $717.54 \mathrm{~cm}^{-1}$ corresponds to strong $\mathrm{C}-\mathrm{Cl}$ stretching and the one at $1219.05 \mathrm{~cm}^{-1}$ corresponds to $\mathrm{C}-\mathrm{N}$ stretching vibrations. The band appearing at $1342.50 \mathrm{~cm}^{-1}$ attributed to $\mathrm{C}-\mathrm{H}$ bending vibration. The band at $1419.00 \mathrm{~cm}^{-1}$ corresponds to asymmetric $\mathrm{C}-\mathrm{H}$ bending. The band at $1658.84 \mathrm{~cm}^{-1}$ corresponds to the symmetrical of $\mathrm{C}=\mathrm{O}$. The band at $1774.57 \mathrm{~cm}^{-1}$ attributes the strong $\mathrm{C}=\mathrm{O}$ stretching and the one at $3417.90 \mathrm{~cm}^{-1}$ corresponds to strong O-H stretching (Karthikeyan et al., 2017).

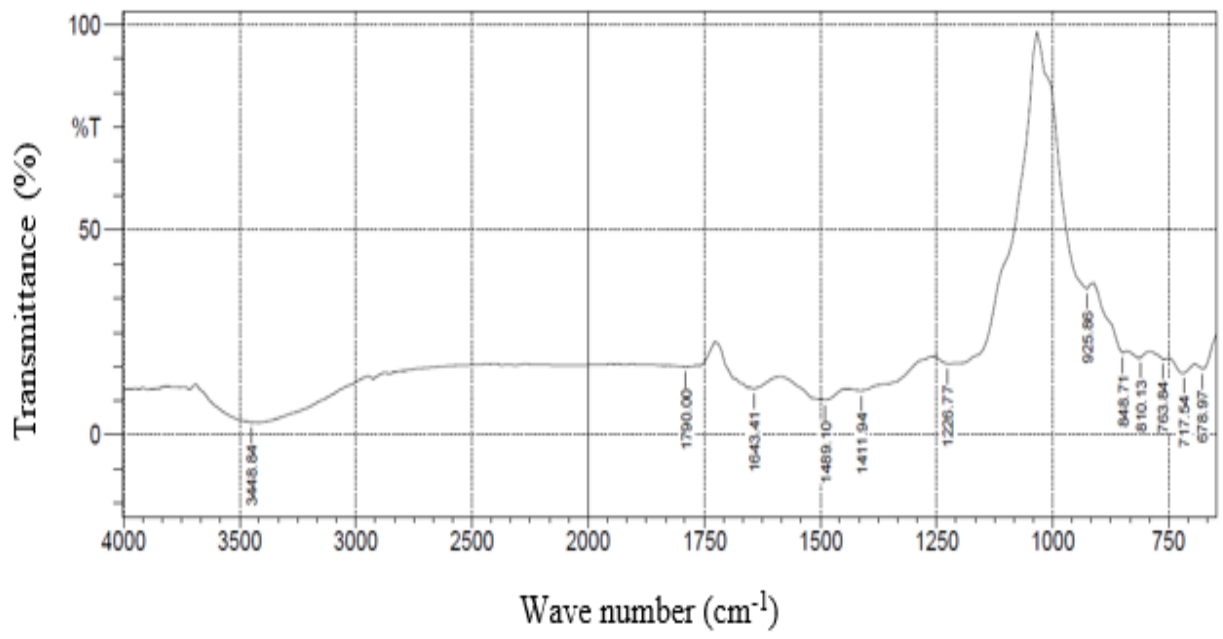

Fig. 3.3: FTIR spectra for $50.0 \%$ Doped $\mathrm{ZnO}$

Fig. 3.3 shows the absorption region of $678.97 \mathrm{~cm}^{-1}, 717.54$ $\mathrm{cm}^{-1}, 763.84 \mathrm{~cm}^{-1}, 810.13 \mathrm{~cm}^{-1}, 846.71 \mathrm{~cm}^{-1} 1226.77 \mathrm{~cm}^{-1}$, $1411.94 \mathrm{~cm}^{-1}, 1489.10 \mathrm{~cm}^{-1}, 1643.41 \mathrm{~cm}^{-1} 1790.00 \mathrm{~cm}^{-1}$ and $3445.84 \mathrm{~cm}^{-1}$. The highest absorbance observed is $97.1 \%$ at a peak $3445.84 \mathrm{~cm}^{-1}$ which corresponds to $2.9 \%$ transmittance. The absorption band observed at $678.97 \mathrm{~cm}^{-1}$ corresponds to $\mathrm{O}=\mathrm{C}=\mathrm{O}$ bending. The absorption band observed at $717.54 \mathrm{~cm}^{-1}$ and $763.84 \mathrm{~cm}^{-1}$ corresponds to C$\mathrm{Cl}$ stretching. The band at $810.13 \mathrm{~cm}^{-1}$ and $846.71 \mathrm{~cm}^{-1}$ attributes C-C skeletal vibrations. The absorption at 1226.77 $\mathrm{cm}^{-1}$ corresponds to $\mathrm{C}-\mathrm{O}$ stretching vibrations. The band at $1411.94 \mathrm{~cm}^{-1}$ and $1489.10 \mathrm{~cm}^{-1}$ corresponds to asymmetric $\mathrm{C}-\mathrm{H}$ bending. The band at $1643.41 \mathrm{~cm}^{-1}$ corresponds to the symmetrical of strong C-H. The band at $1790.00 \mathrm{~cm}^{-1}$ attributes the $\mathrm{C}=\mathrm{O}$ stretching and $3445.84 \mathrm{~cm}^{-1}$ attributes $\mathrm{O}$ $\mathrm{H}$ stretching (Ajai \& Sangshetty, 2017). The $50 \%$ doped composites showed the highest absorption which indicates increase in absorption as doping quantity increases. 
C. SEM
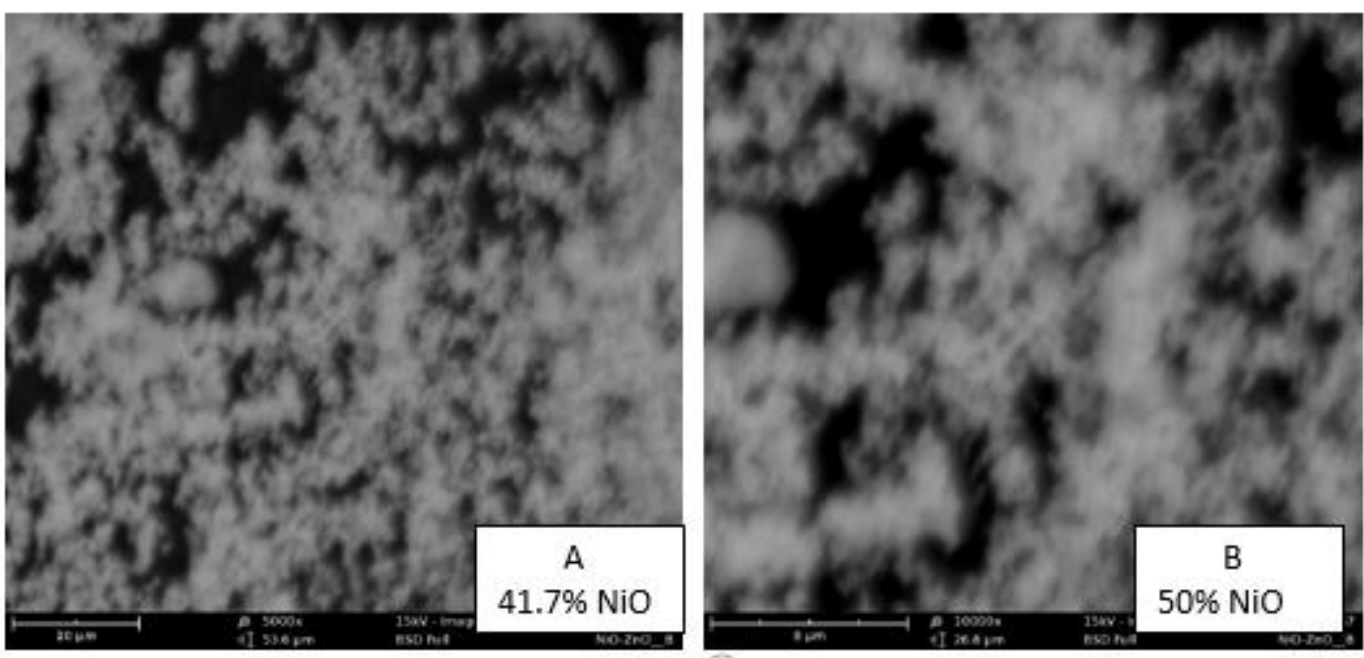

Fig. 3.4: SEM micrographs for doped composites

Fig. 3.4(A) shows a micrograph with whitish colour image agglomerated with dark dotes of $\mathrm{NiO}$ (Karthikeyan et al., 2017). Due to the density of the sample in Fig. 3.4(A), more light were able to pass through it which is evident in the FTIR analysis. Observation on Fig. 3.4(B) shows that the zinc oxide and filler are sparsely dispersed through the matrix of the composite materials, and visible traces of white and black coloring are seen indicating the equal percentage of mixture in the sample (Yakubu et al., 2015).

\section{CONCLUSION}

The synthesis of a doped $\mathrm{ZnO}$ composites using simple solid stated method was successfully carried out in this research. Based on the objectives of this research, investigations were carried out for the dielectric constants using open ended coaxial probe (OECP), FTIR for bonding and IR absorption and SEM for morphology. From the result, it was found that as $\mathrm{NiO}$ content is increased, both dielectric constant and IR absorption increases and the more the particles agglomerate. It is therefore concluded that $\mathrm{NiO}$ can be used as a filler for improving dielectric constant with $\mathrm{ZnO}$ as a matrix. The composite $(\mathrm{NiO} / \mathrm{ZnO})$ can serve as a good agent for constructing capacitors and other dielectric based materials that can be used in constructing electronic and telecommunication gadgets.

\section{REFERENCE}

[1] Ahmad, F. A., Zulkifly, A., Suzan, J. O., \& Abdalhadi, D. M. (2017). Improvement of Dielectric, Magnetic and Thermal Properties of OPEFB Fibre-Polycaprolactone Composite by Adding Ni-Zn Ferrite. Polymers 2017, 9, 1-15.

[2] Ahmad, F., Zulkifly, A., Mohamad, F. Z., Suzan, J., \& AbuBakar, Y. (2015). Dielectric characterization of oil palm fiber reinforced polycaprolactone-nickel oxide composite at microwave frequency. Procedia Environmental Sciences, 30, $273-278$.

[3] Ajai, K. S. M., \& Sangshetty, K. (2017). Preparation, Structural and Dielectric Properties of Polyaniline-Nickel Ferrite Composites. International Journal of Materials Science, 12, 4756.

[4] Albert, O. J., \& Abiola, M. (2017). Synthesis and structural analysis of $\mathrm{ZnO}-\mathrm{NiO}$ mixed oxide nanocomposite prepared by homogeneous precipitation. Ceramics International, 43(2017), $15424-15430$.
[5] Aldar, B. A., Pinjari, R. K., \& Burange, N. M. (2014). Electric and Dielectric Behaviour of Ni-Co-Cd Ferrite. IOSR Journal of Applied Physics (IOSR-JAP), 6, 23-26.

[6] AzoNano, (2013), Nickel Oxide (NiO) Nanoparticles: Properties, Applications. Retrieved from www.azonano.com/article.aspx ?ArticleID $=3378$ on $7^{\text {th }}$ February, 2019.

[7] Bahari, A., Roodbari, S. M., Derahkshi, M., \& Jamali, M. (2012). Organic Thin Film Transistors with Polyvinylpyrrolidone / Nickel Oxide Sol-Gel Derived Nanocomposite Insulator. Journal of Nanostructures, 2, 313316.

[8] Banerjee, M., Mukherjee, S., \& Maitra, S. (2012). Synthesis and Characterization of Nickel Oxide Doped Barium Strontium Titanate Ceramics. Cerâmica, 58, 99-104.

[9] Gaurav, J., Jai, P., Achu, C., Jitendra, G., Srivastava, A. K., \& Biradar, A. M. (2015). Effect of Nickel Oxide Nanoparticles on Dielectric and Optical Properties of Nematic Liquid Crystal. AIP conference Proceedings, 1675, 1-8.

[10] Ghassan, A., \& Naeem, M. (2016). Effect of Temperature and Nickel Concentration on the Electrical and Dielectric Properties of Polyethylene-Nickel Composites. Ibn Al-Haitham J. for Pure \& Appl. Sci., 29 (1), 59-72.

[11] John, J., Abdul, K., Lonappan, A., \& Mathew, K. T. (2008). Microwave Dielectric Properties of Nanostructured Nickel Ferrite. Bull. Material Science. 31, 847-851.

[12] Karthikeyan, V., Padmanaban, A., Dhanasekaran, T., Praveen Kumar, S., \& Gnanamoorthy, G. (2017). Synthesis and Characterization of $\mathrm{ZnO} / \mathrm{NiO}$ and Its Photocatalytic Activity. Mechanics, Materials Science \& Engineering Journal, 9.

[13] Latif, I., Entisar, E., AL-Abodi, D., Badri, H., \& Jawad, A., (2012). Preparation, Characterization and Electrical Study of (Carboxymethylated Polyvinyl Alcohol/ZnO) Nanocomposites, American Journal of Polymer Science 2012, 2(6), 135-140.

[14] Mansour, A.F., Mansour, S.F. and Abdo M. A., (2015. Improvement Structural and Optical Properties of $\mathrm{ZnO} / \mathrm{PVA}$ Nanocomposites. IOSR Journal of Applied Physics (IOSR-JAP), 7,60 .

[15] Muhammad, J., Shahid, A., \& Shahzad, N. (2012). Synthesis and Characterization of Structural, Electrical and Magnetic Properties of $\mathrm{NiO}$ Nanocrystallites. Advances in Civil, Environmental and Materials Research (ACEM), 12, 885.

[16] Nisha, J. T., Raveendran, R., Alexandra, V. V., \& Chithra, P. G (2008). Optical, electrical and structural studies of nickel-cobalt oxide nanopartilces. Indian Journal of Engineering and Material Sciences, 15, 489-496.

[17] Osama, A. D., Mostafa, M. H., Khalil, K., \& Hamdy, A. K. (2014). Microstructure and Dielectric Properties of $\mathrm{ZnO}_{-} \mathrm{SiO}_{2}$ $\mathrm{NiO}$ Composite. International Journal of Science and Research (IJSR), 316-323. 
[18] Rajashekhar, B., Vishnuvardhan, T. K., Shashidhar, N., Satishkumar, K. B., Basavaraja, C., \& Chandrashekhar, M. (2015). Synthesis, Characterization and Study of Electrical Properties of Polyaniline-NiO Nanocomposites. International Journal of Research in Engineering and Applied Sciences. 5(7), 36-46.

[19] Raju, P., \& Murthy, S. R. (2012). Preparation and characterization of $\mathrm{Ni}-\mathrm{Zn}$ ferrite + polymer nanocomposites using mechanical milling method. Appl Nanosci (2013), 3, 469475.

[20] Ramesh, P., Craig, G., Dinesh, A., \& Rustum, R. (2003). Ultralow dielectric constant nickel-zinc ferrites using microwave sintering. J. Mater. Res., 18, 2292-2295.

[21] Ranga, G., Mohan, D., Ravinder, A. V., \& Ramana, R. B. (1999). Dielectric properties of polycrystalline mixed nickelzinc ferrites. 40, 39-45.

[22] Sani, G. D., Yakubu, A., \& Sahabi, S. (2019). Nickel Oxide (NiO) Devices and Applications: A Review. International Journal of Engineering Research \& Technology (IJERT), 8(04), 461-467.

[23] Sourav, D., Lalla, N. P., \& OKram, G. S. (2014). Synthesis, characterisation and dielectric properties of nanocrystalline
Nickel. Indian Journal of pure and applied physics, 52, 386390.

[24] Suresh, S., Kaushik, P., Zaira, Z. C., and Enamul, H., (2017). Structural, dielectric and optical investigation of chemically synthesized Ag-doped $\mathrm{ZnO}$ nanoparticles composites, Journal of Sol-Gel Science and Technology, 77, 3.

[25] Sylvestre, A., Kukiełka, S., Nguyen, D. M., Gulbiński, W., \& Pauleau, Y. (2007). Dielectric Properties of Nickel Containing Hydrogenated Amorphous Carbon Films Prepared By Microwave Plasma-Assisted Deposition Technique. Rev .adv. mater. sci., 15, 185-195.

[26] Umit, O. (2010). ZnO Devices and Applications: A Review of Current Status and Future Prospects. Proceedings of the IEEE, 98(7), 1255-1268

[27] Wang, F., Yan, D., Su, Y., Lu, Y., Xia, X., \& Huang, H., (2017) Research on the Dielectric Properties of Nano-ZnO/Silicone Rubber Composites. IOP Conf. Series: Materials Science and Engineering, 231(2017), 2-8.

[28] Yakubu, A., Zulkifly, A., Nor Azowa, I., \& Ahmad, F. (2015). The Effect of $\mathrm{ZnO}$ nanoparticles Filler on Complex Permittivity of ZnO-PCL Nanocomposite at Microwave Frequency. Physical Science International Journal, 6(3), 196-202. 